\title{
Mapping and Analysis of the Reactive Power Balance in the Danish Transmission Network
}

\author{
Mads Øbro Nannestad ${ }^{1,2, *}$, Zhe Zhang ${ }^{1}$, Jundi Jia ${ }^{1}{ }^{(0)}$, Emil Kjær Jensen ${ }^{2}$ and \\ Peter Jan Randewijk ${ }^{3}$ \\ 1 Center for Electric Power and Energy, Technical University of Denmark (DTU), 2800 Kgs. Lyngby, Denmark; \\ zz@elektro.dtu.dk (Z.Z.); junjia@elektro.dtu.dk (J.J.) \\ 2 Energinet, Tonne Kjærsvej 65, DK-7000 Fredericia, Denmark; EKJ@Energinet.dk \\ 3 Center for Bachelor of Engineering Studies, Technical University of Denmark (DTU), DK-2750 Ballerup, \\ Denmark; petra@dtu.dk \\ * Correspondence: mads.nannestad@gmail.com; Tel.: +45-30694287
}

Received: 11 December 2018; Accepted: 28 January 2019; Published: 29 January 2019

check for updates

\begin{abstract}
This paper investigates the reactive power balance of the Zealand side of the Danish transmission system (DK2) by using QV-curves. The study is performed in cooperation with Energinet, who is the Danish transmission system operator (TSO). Firstly, this paper aims to map the reactive power balance with the current challenges in the system, which appears due to a decision of changing overhead lines in the scenic area to cables. Secondly, a method is derived for obtaining a comprehensive overview of the impacts that future projects might have on the system. By dividing the transmission system into smaller areas, it is possible to analyze how the reactive power will affect the voltage; moreover, it is favorable to analyze and handle the challenges in the reactive power balance locally. This helps the TSO to quickly determine the lack of reactive power devices and issues that might occur in future expansions of the system. For this paper, a full-scale model of DK2 and SCADA-data has been utilized. It covers the period from 01-01-2016 to 20-08-2017 between the TSO and the Distribution System Operator (DSO). The studies have shown how the location of the wind production will create issues in the reactive power balance.
\end{abstract}

Keywords: reactive power mapping; reactive power compensation; QV-analysis; QV-curves

\section{Introduction}

Reactive power is needed to transfer active power in an AC-system. The reactive power stored in the AC-system, which is constantly changing state between being stored in electrical fields (capacitive) and magnetic fields (inductive), is also called the oscillating power [1]. The overall reactive power for the system must always be balanced. However, local imbalances in the system can occur, which will affect the voltage [2,3] by increasing or decreasing voltage magnitude. Reactive power is associated with a voltage changes and thus does not have the ability to be transferred over long distances, whether physical or electrical length. This means that the reactive power must be handled locally [4]. Therefore, there is a need to manage both the current reactive power balance and to maintain the reactive power balance when designing future projects in the electrical power system.

The modern energy systems tend to have a higher penetration level of renewable energy sources, such as wind- and solar power. These types of energy sources are usually not located in the most populated areas, and the power must be transferred from the source to the consumers. Moreover, the development of electrical systems in many countries means that the system is going towards the use of cables, instead of overhead-lines [5]. This is especially applicable for the distribution systems, but it is also the case for some transmission systems. Many countries have a fixed limit 
for the reactive power exchange between two systems-TSO-DSO (Transmission System Operator, Distribution System Operator) or TSO-TSO-based on a specific power factor, which can deviate from $0.85-0.95$ [5].

The Danish transmission system is divided and separated into two frequency areas, DK1 and DK2. DK1 is the larger of the two systems, including the western part of Denmark, and is synchronized with the Continental European Grid [6]. However, DK2 is the eastern part of Denmark and is synchronized with the Nordic synchronous area [6]. This paper will only focus on investigation of the reactive power balance in DK2 as illustrated in Figure 1.

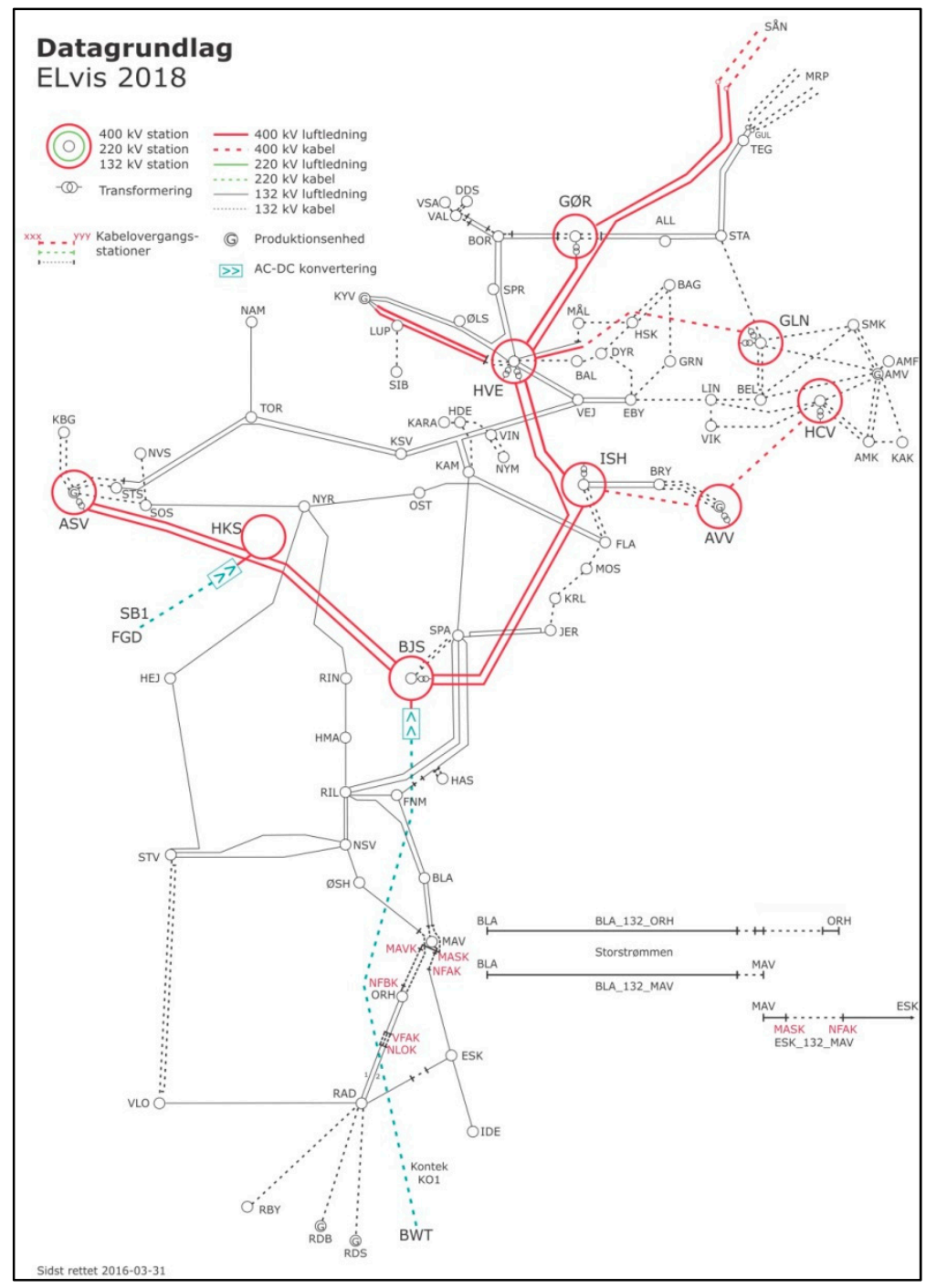

Figure 1. Map of the Danish transmission system, DK2.

Based on the decision of changing the overhead lines to cables in urban and scenic areas in Denmark, the electrical power system has slowly started to change from a predominantly inductiveto a predominantly capacitive system $[7,8]$. Furthermore, the decision to split the Danish system into a transmission- and distribution part, with a superficial boundary of $100 \mathrm{kV}$, has compounded the problem. These changes have a deeper and more pronounced effect on the reactive power balance in the transmission system, due to the location of the main wind production in DK2. The main production is in the southern part of DK2, as seen at the bottom of Figure 1, where there is a low population. This means that the loading on the cables in the southern part varies from highly loaded, when a high amount of wind energy is generated, and low load, when the wind production is low. The cables are 
illustrated as the dotted lines in Figure 1 in which all the substations in the Danish system have a unique three-letter name, such as RAD (Radsted).

Traditionally, the analysis of the required reactive power has been calculated based on the exchange between the TSO and DSO. The needed reactive compensation has been calculated based on a power factor limit of 0.95 , for the maximum exchange active power between the two systems. By defining a reactive power limit, one can compare the historical measurements. Based on the comparison between the limit and historical data, it can be determined whether there is a lack of reactive power in a specific interface between the two systems. The idea is to create two interdependent systems. This method of analyzing the needed reactive power devices is only clarifying the problem at a specific point of the transmission system. By only analyzing a specific interface between the TSO and DSO, one does not take the dynamics of a larger system into account.

In this paper, a QV-analysis [2] has been conducted in cooperation with Energinet. The full scale PowerFactory model of DK2 and measurements of the power flow, as well as the voltage magnitudes, have been provided by Energinet. The measurements are taken from the secondary side of the transformer between the different voltage levels of the transmission system. The imported power, consumption, and production are provided from Energinet's publicly available data [9], which was uploaded to the model. The analysis will display how to use QV-curves [10] to determine the need for reactive compensation, and the placement of the needed reactive power devices. The analysis is based on worst case scenarios, and the case selected for the investigation is when the largest exchange of reactive power between TSO and DSO occurs. The QV-analysis shows the lack of reactive power depending on the voltage stability, which is the power system's ability to withstand different contingencies [11,12]. This paper will also investigate how the future installations in the transmission network will impact on the reactive power balance. Furthermore, the result will be discussed and compared to the results obtained by the traditional practice, from a TSO point view.

The rest of this paper is organized as follows. The data handling from the supervisory control and data acquisition (SCADA) viewer is explained in Section 2. To make the analysis more manageable, the transmission system has been divided into different areas. The analysis will investigate the lack of reactive power locally, by statically calculating and defining the weak bus bars in the Mvar area [13], which is presented in Section 3. The main findings of the analysis have been in the southern part of Denmark. This is, as expected, due to the large amount of wind power and the amount of cables in the transmission system. The analysis of the reactive power balances has been carried out by using QV-curves to determine the required reactive power, as a function of the voltage in Section 4 . In addition, the QV-analysis is also further discussed. Finally, the conclusion is given in Section 5.

\section{Data Processing}

All the data used in this paper has been obtained from a historical database. The database has a time span from 01-01-2016 to 20-08-2017, which holds all the measurements from Energinet's SCADA system. The measurements are from the interface between the transmission- and distribution system. It was chosen to investigate the contribution from the lower voltage levels, which, in the southern area, implies the main part of the onshore wind production. For this paper, the location of the installed onshore wind power was not investigated, which has a total capacity of $650 \mathrm{MW}$ on Zealand. It is assumed that most of the capacity is installed in the southern part of Zealand, where there is a low population density and a high amount of wind. In the southern area there are two of the larger offshore wind farms on Zealand, they are connected, see Figure 1, as RDS and RDB. Roedsand I (RDS) has a total capacity of $165 \mathrm{MW}$ and Roedsand II (RDB) has a total capacity of $215 \mathrm{MW}$.

\subsection{Data Verification}

It is necessary to ensure that the data obtained from SCADA is correct regarding sign convention. This is to ensure that the flow direction through the transformer is correct. It is likewise necessary to 
validate the magnitude of voltages, active power, and reactive power, to ensure a correct scalar factor in the SCADA system.

The installed capacity of wind turbines exceeds the consumption level in the southern part of Zealand. This fact makes it possible to validate the data from stations, with a large amount of wind turbines connected to the distribution network. The measurements from a station with a high wind penetration connected to the distribution network, should indicate a flow through the $132 / 50 \mathrm{kV}$, $132 / 30 \mathrm{kV}$ and $132 / 10 \mathrm{kV}$ transformers towards the transmission network.

Figure 2 shows a scatter plot from a substation in the southern area, called VLO, where all the measurement from each hour is plotted. This shows a power flow from the distribution side, to the transmission side. This observation matches the expectation for this area, and shows that the consumption in general is lower than the production. It is then possible, based on the scatter plot, to verify the sign convention from the measurement, when it matches the expected power flow, by consolidating the measurement with a known date of time of a high wind production. This is found by using the publicly available data from Energinet [9] — the sign convention of the power flow can be confirmed.

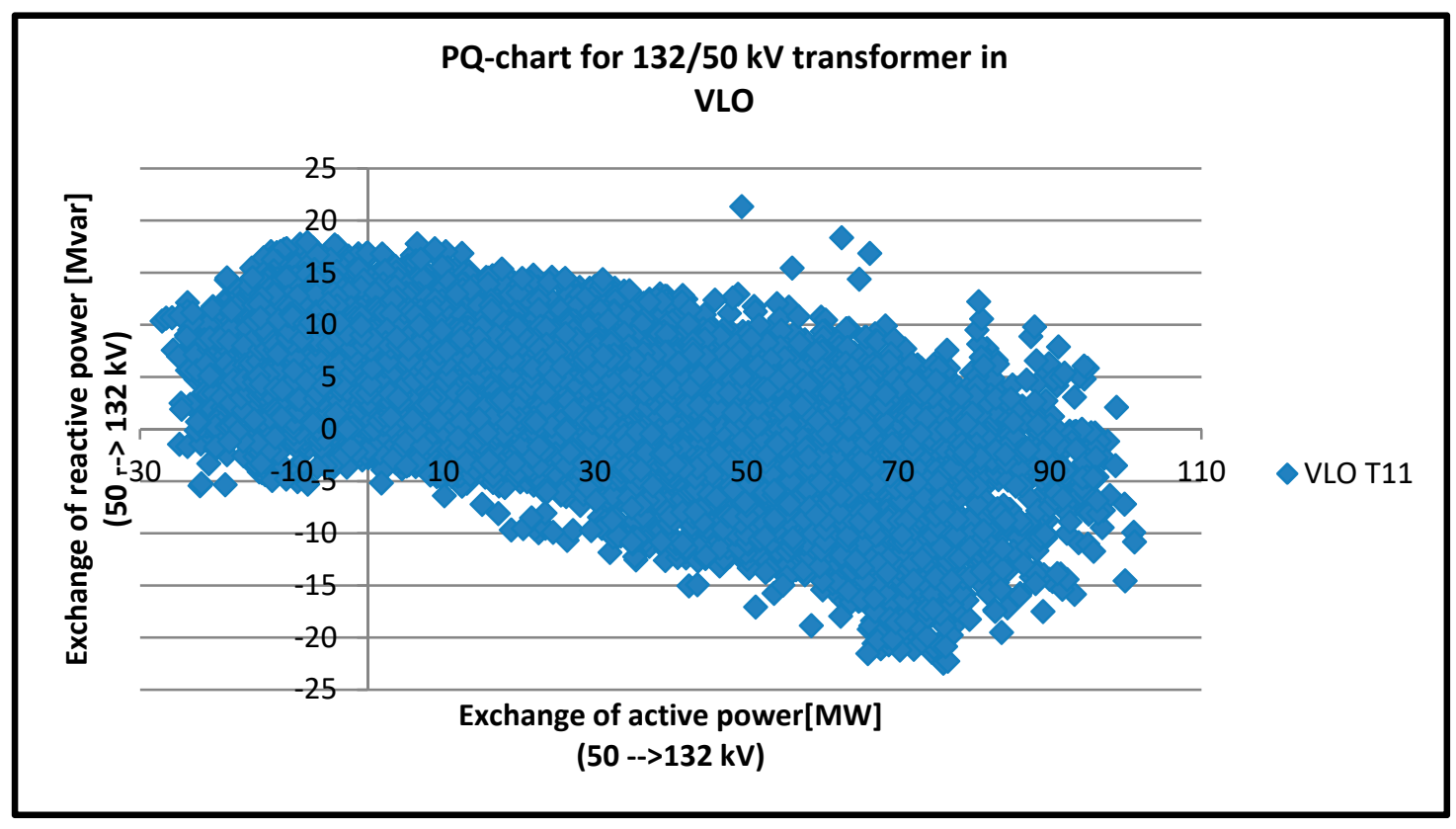

Figure 2. Scatter plot of $132 / 50 \mathrm{kV}$ at substation VLO. Positive sign convention indicates the flow direction from the distribution side, to the transmission side.

\subsection{Discarded Data}

The data needed for this paper are the worst-case scenarios of reactive power flow. In some cases, the worst case of reactive power through the transformer was too distant from the normal operation, and was therefore not selected for the analysis. With the rather large amount of data, it would be a huge task to validate specific data points for all transformers. For this reason, data points that are too far from the normal operation area of the transformer has been discarded.

An example is shown in Figure 3, with the transformer at station IDE. The data point marked with a red circle is the situation with the highest amount of reactive power flowing towards the transmission network. Since the data point is so far from the transformer's normal operation area, this point is discarded, and the data points marked with red dots has been chosen instead. 


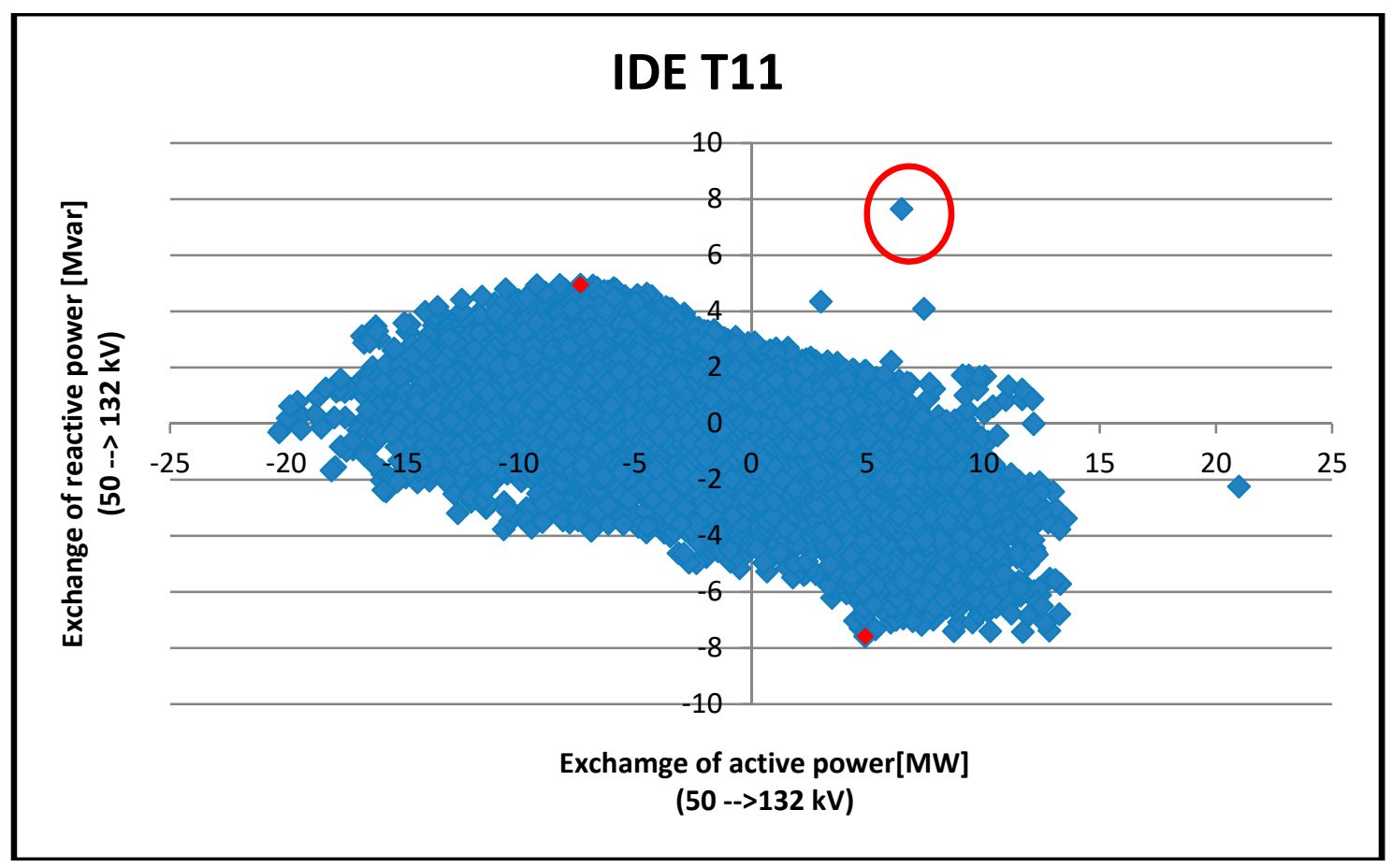

Figure 3. Scatter plot for the substation IDE T11 132/50 kV. The red circle highlights the discarded data points.

\section{Mvar Areas}

Due to the reactive power's disability of transferring over long distances, DK2 was originally divided in 5 Mvar zones, Figure 4a. However, due to the low impact the reactive power had throughout the analysis on the middle area (orange) and the Copenhagen (light green), it was decided to divide the two areas even further, as it is shown in Figure $4 \mathrm{~b}$. Changes of the reactive power flow in the two large areas does not affect the voltage, and it is therefore required to shorten the distances from the defined zone's center to the outer substations. The idea of defining these zones is to look at the transmission system in smaller areas, which makes it easier to investigate the reactive power balance based on simple QV-curves. Furthermore, the Mvar areas can simplify the calculations for the required compensation by placing the device in the middle of the area, which will then affect the voltage in the whole area. Therefore, the overall cost of the compensation devices can be minimized.

\subsection{Traditional Mapping of the Reactive Power Balance}

Traditionally, the reactive power balance between the DSO and TSO were treated as two separate systems. This means that there is a limit for the transmitted reactive power between the two systems, which is calculated by a preferred power factor (here for Denmark this power factor is 0.95). This method can be visualized in Figure 5, where the accepted power flow is within the red box. The size of the limit (the red box) are calculated by adding an expansion factor of $10 \%$ of the maximum active power, and then calculate a maximum reactive power exchange between the DSO and TSO. 


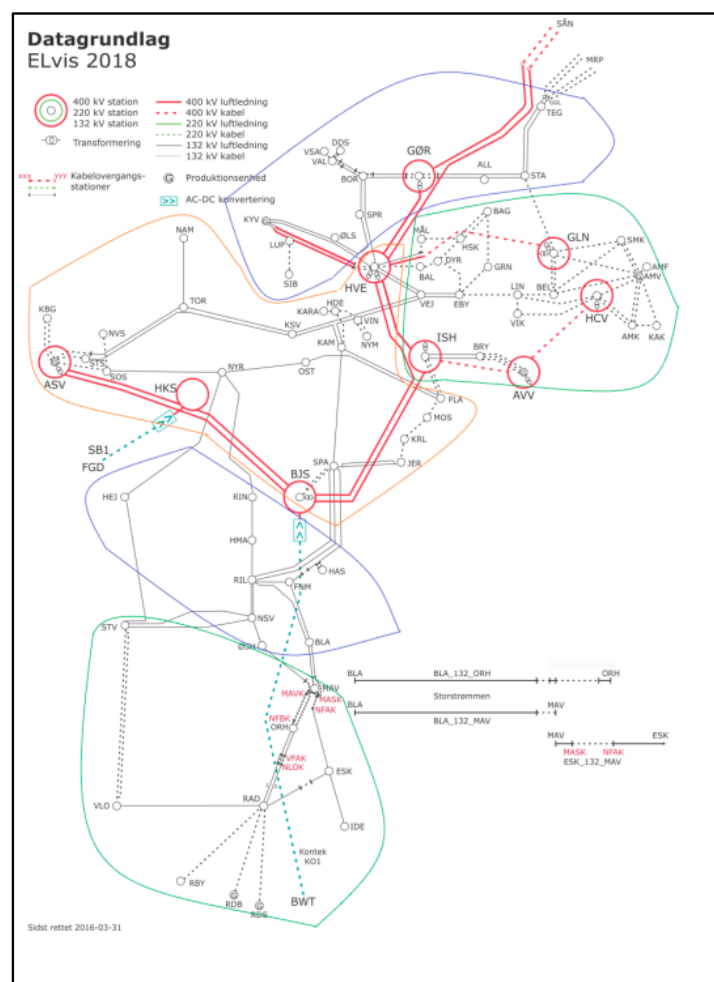

(a)

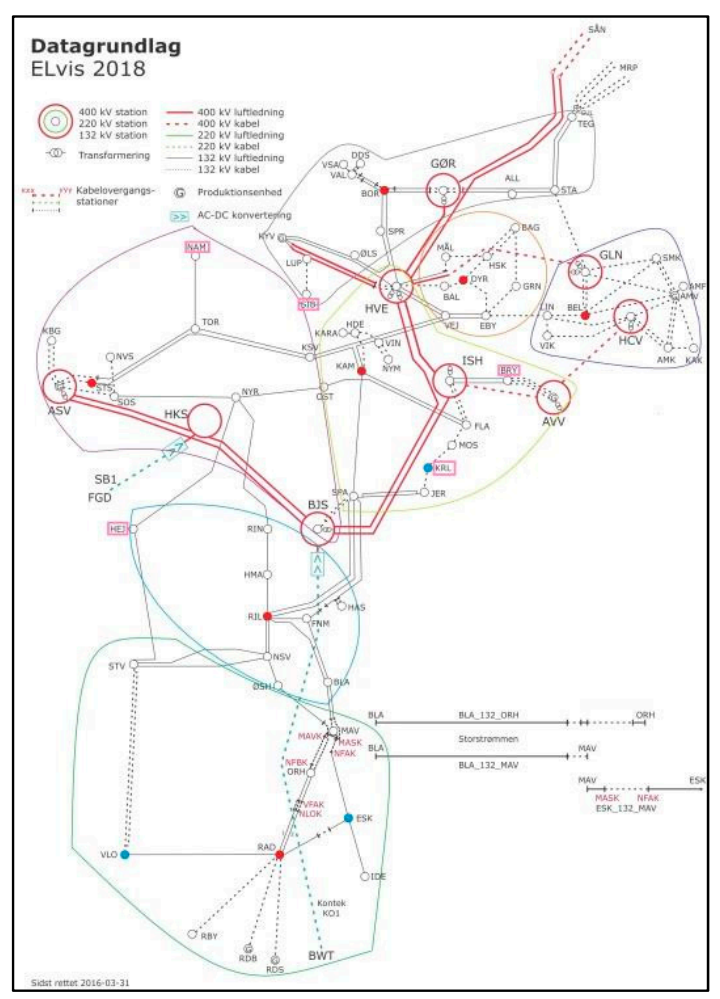

(b)

Figure 4. These are Figures of DK2: (a) Is DK2 divided in 5 Mvar zones, based on earlier Energinet analysis. (b) Is DK2 divided in 7 Mvar zones, based on the analysis for this paper.

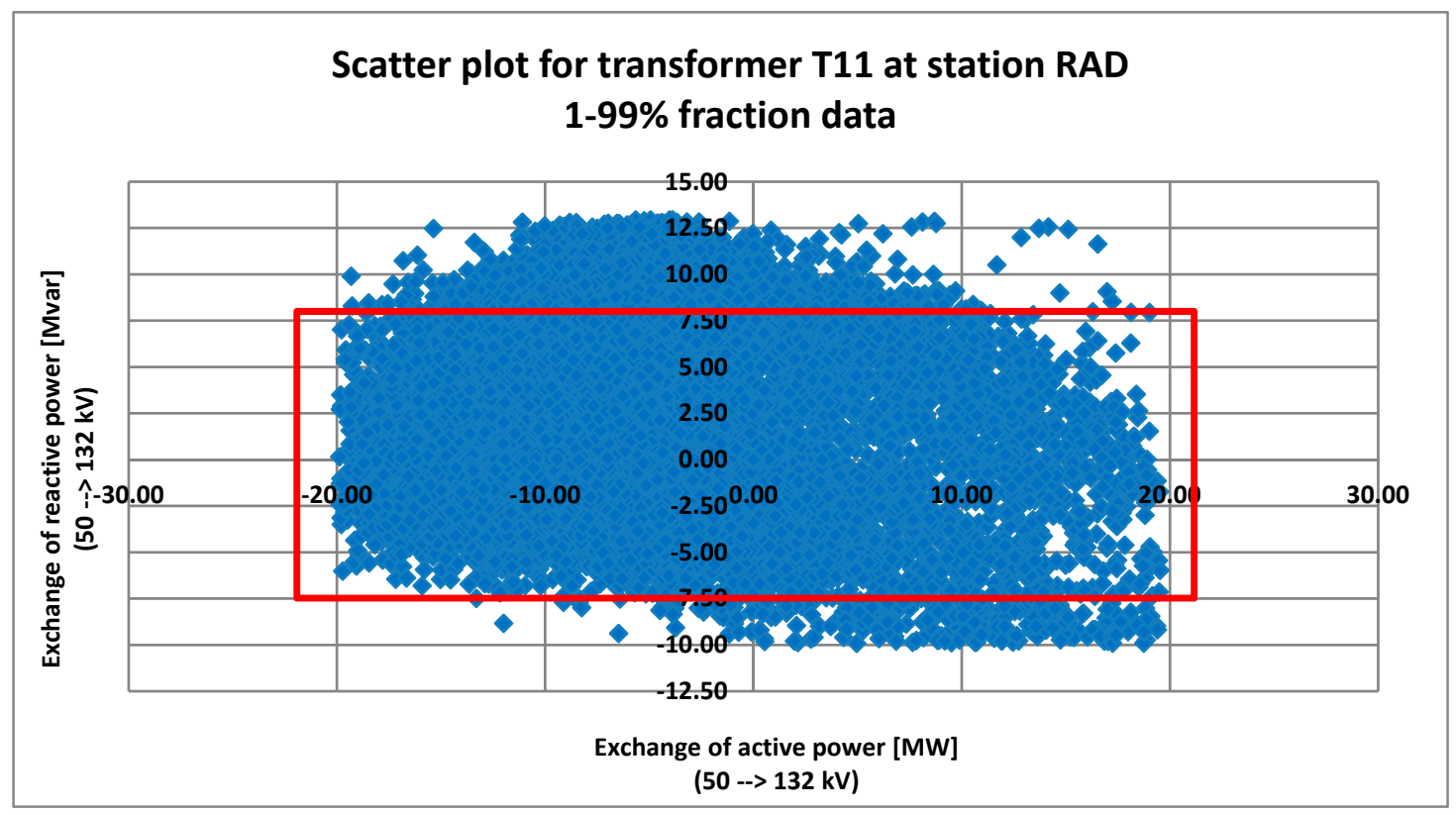

Figure 5. Scatter plot for transformer at station RAD where 1-99\% fraction data is used. The red rectangle indicates acceptable limits for the transfer of power.

By investigating the reactive power, as described above, a wrong picture of the needed reactive power compensation may result. This method only investigates whether the reactive power through the interface between two system is too high, but the load is often inductive, which helps lowering the voltages of the capacitive transmission network. Using the divided Mvar areas in QV-analysis to investigate the whole system quickly shows the actual needed reactive power in the area. In Figure 6 
there is an example of an analysis done by the traditional way of analyzing the reactive power contribution from the lower voltage levels. The results from the Figure 6 are from the southern part of Zealand.

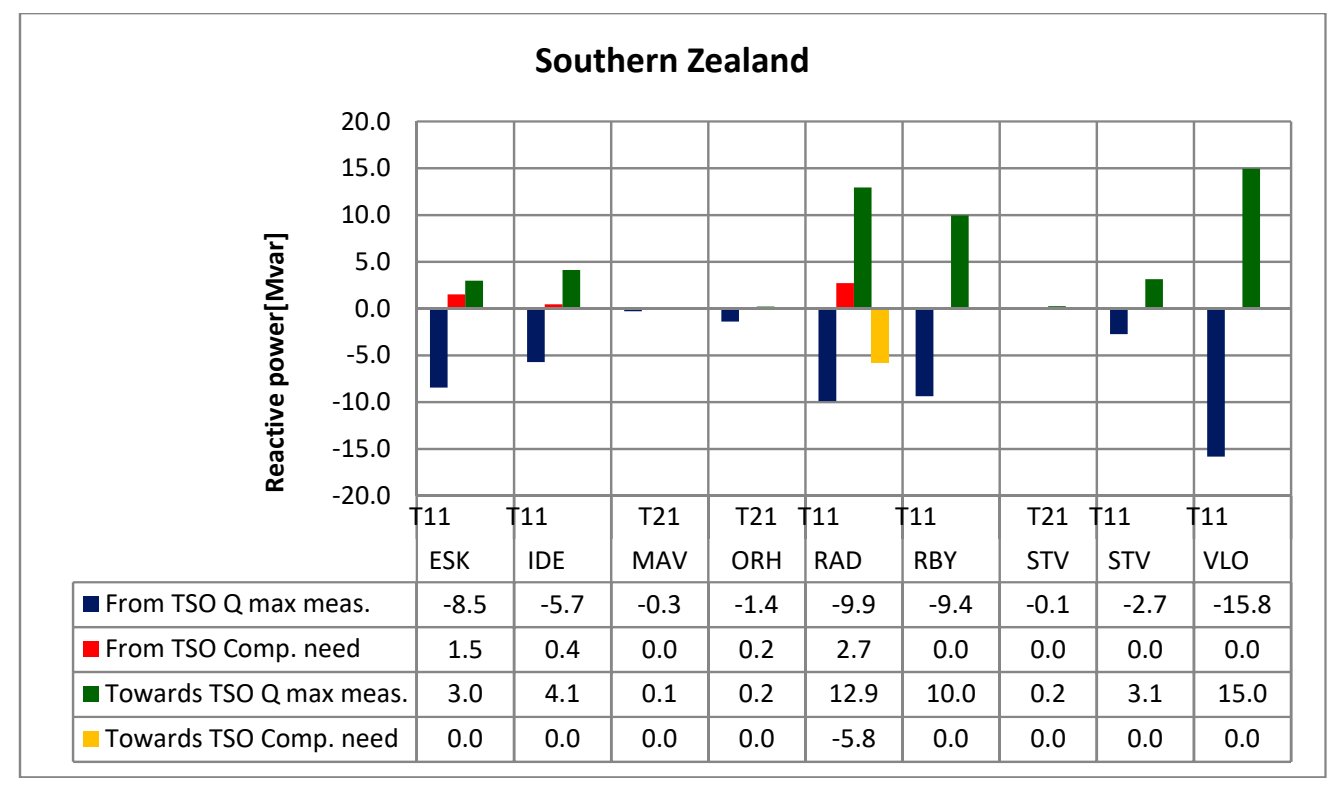

Figure 6. Bar-chart showing highest measured flow of reactive power and the indicate requirement for compensation, in the southern Zealand.

\section{Analysis}

An analysis of the two worst case scenarios, as it was determined in Section 2, i.e., 1) low load and high wind, and 2) low load and low wind, was conducted. These two cases were selected as the top and bottom of the reactive power from the scatter plot for the area. Both cases are shown in Tables 1 and 2, respectively, whereas the power balances for the two cases were uploaded to the model provided by Energinet. The reactive power flow for the system will be analyzed in N, N-1 and N-2, by ENTSO-E standards [14], where exceptional contingencies are not considered.

Table 1. Exchange of reactive power towards the transmission system operator (TSO), a high wind and low load scenario.

\begin{tabular}{ccccc}
\hline Busbar & Timestamp & MW & Mvar & kV \\
\hline ESK & 04-06-2017 03:00 & -6.64 & 1.03 & 52.69 \\
IDE & $04-06-201703: 00$ & -4.74 & 2.74 & 52.69 \\
RAD & $04-06-201703: 00$ & -6.07 & 12.67 & 52.27 \\
RBY & $04-06-201703: 00$ & 0 & 0 & 0 \\
STV & $04-06-201703: 00$ & -5.23 & 1.62 & 52.62 \\
VLO & $04-06-201703: 00$ & -11.02 & 17.24 & 52.99 \\
\hline
\end{tabular}

Table 2. Exchange of reactive power away from the transmission system operator (TSO), a low wind and low load scenario.

\begin{tabular}{ccccc}
\hline Busbar & Timestamp & MW & Mvar & kV \\
\hline ESK & 02-02-2016 10:00 & 3.78 & -8.94 & 51.69 \\
IDE & 02-02-2016 10:00 & 7.12 & -5.92 & 51.60 \\
RAD & $02-02-201610: 00$ & 6.78 & -13.33 & 51.66 \\
RBY & $02-02-201610: 00$ & 19.87 & -10.66 & 51.47 \\
STV & $02-02-201610: 00$ & -6.14 & -1.63 & 51.99 \\
VLO & $02-02-201610: 00$ & 75.94 & -22.45 & 50.59 \\
\hline
\end{tabular}




\subsection{Preconditions for the $Q V$-analysis}

To make sure that the system can handle the reactive power imbalances created in the contingencies, the dynamic responses are not part of the analysis of this paper. The dynamic compensation devices, such as SVC and the synchronous condenser, are limited to $20 \%$ of their maximum output. Therefore, a dynamic reserve for large disturbances (transient events) is insured [15,16].

The nominal voltage is 1 p.u., though it should be noticed that the operational voltage is normally slightly above. The chosen limits for this analysis are 1.06 and 1 p.u., which can be seen in Table 3 .

Table 3. The grid code and define limits for the analysis.

\begin{tabular}{ccc}
\hline & Voltage Limits \\
\hline & Maximum Voltage Limit & Minimum Voltage Limit \\
\hline Defined system limits & 1.06 p.u. & 1 p.u. \\
Grid code limit [17] & 1.1 p.u. & 0.9 p.u. \\
\hline
\end{tabular}

The defined upper limit at 1.06 p.u. is chosen to ensure a significant margin to the voltage limit [18], given by the grid code in the above Table 3. It is important to dimension the system with a margin in steady state when designing the reactive power balance of a system, to prevent a possible voltage collapse. The lowest chosen are limited to 1 p.u., because of the resistive losses lower the voltage too much.

In this analysis, maintenance plans for the system will not be considered. The studies are performed on a fully operational system, with only outages of transformers between the TSO and the DSO. ENTSO-E regulations state that the N-1 and N-2 do not imply maintenance outages.

\subsection{Contingency Analysis for the QV-analysis}

Eight substations are implied in the southern area. When the southern areas were investigated, the substation RAD was chosen as the central station, where the required reactive power will be calculated from. RAD is selected due to its central placement in southern area and is marked with a red dot in Figure 1. In the normal operation, there were not any challenges with the voltage limit given in Table 3. The contingency analysis was made afterwards, to investigate the challenges that could appear in the system. The following contingencies, shown in Table 4, resulted in voltages above the maximum limit chosen for this analysis. To investigate the contingencies further, a sweep with multiple power balances was carried out [19] to determine the worst scenarios. The two selected contingencies based on the contingency analysis were, no. 2 and 3 from Table 4, both low load and low wind cases. These two cases are then used in the analysis.

Table 4. The contingencies which are creating over voltages in the southern area.

\begin{tabular}{ccc}
\hline \multicolumn{3}{c}{ Outcome of the Contingency Analysis } \\
\hline Contingency No. & Contingency Name (N-2) & Contingency Devices \\
\hline 1 & RAD_132-R12 \& STV_132-R11 & 2 Reactors \\
2 & MAV_132-R11 \& RAD_132-R12 & 2 Reactors \\
3 & ESK_132_MAV \& RAD_132-R12 & OH-line \& Reactor \\
4 & RAD_132-R12 \& STV_132_VLO & Reactor \& OH-line \\
\hline
\end{tabular}

\subsection{Analysis}

It was discovered that contingency no. 3 was the case in which the voltage increased the most. Figure 7 shows a QV-analysis of the N-2 contingency, where the transmission line was disconnected between ESK and MAV, and the reactor at RAD. The three stations, RAD, RBY, and VLO, cross the voltage limit. A double busbar is installed at RAD, and the two busbars have the same characteristic in 
Figure 7. By using the QV-analysis, it was possible to see that the highest voltage was not the bus bar that lacked the most inductive power. This is due to the voltage sensitivity, which is higher at bus RBY than RAD, where RAD had a lack of 87 Mvar in Figure 7. Based on Figure 7, a 100 Mvar reactor at RAD was selected to maintain the voltage under the defined limit. The 100 Mvar reactor was selected due to standard sizing of reactors.

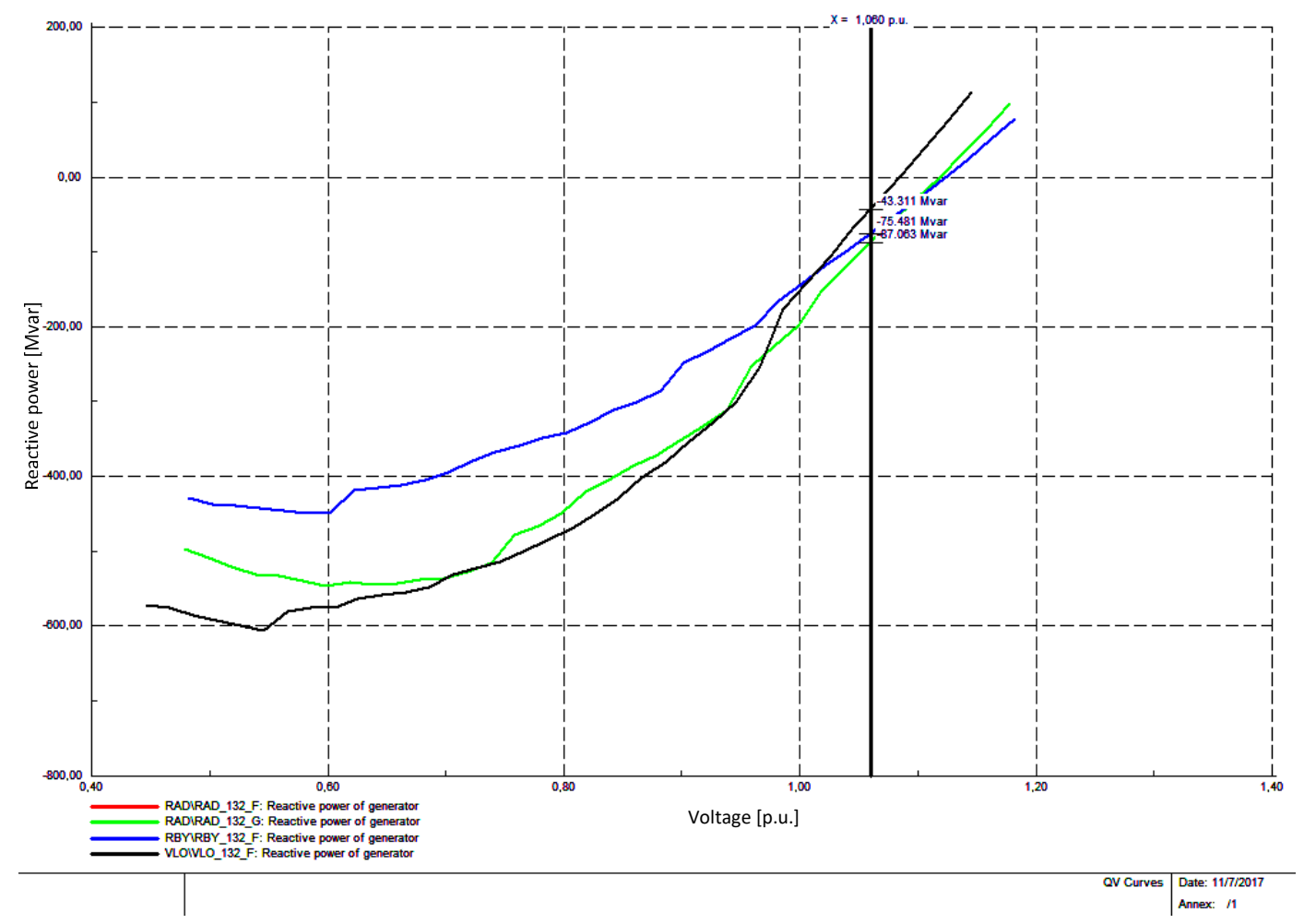

Figure 7. QV-analysis of the 3rd contingency, in the southern area of Zealand.

By adding a 100 Mvar reactor at the bus bar RAD, the voltage levels were lowered below the desired maximum limit for the voltage from Table 3, which is shown on the graph in Figure 8. All the bus bars in the area are plotted, to make sure that none of them is lower than the minimum desired voltage limit. The bus bar nearest the limit are still RBY, which were expected. The colors of the curves are given in Table 5, which compares the result of the analysis.

Table 5. The comparison between the two cases of reactive power compensation.

\begin{tabular}{cccc}
\hline \multirow{2}{*}{ Busbar } & \multicolumn{3}{c}{ Comparison between the Ways of Additionally Compensate the Area } \\
\cline { 2 - 4 } & Graph Color & $\begin{array}{c}\text { Displacement from the } \\
\text { Upper Voltage Limit after 100 } \\
\text { Mvar Compensation (Mvar) }\end{array}$ & $\begin{array}{c}\text { Displacement from the Upper } \\
\text { Voltage Limit after 50/50 Mvar } \\
\text { Compensation (Mvar) }\end{array}$ \\
\hline ESK & Red & 15.245 & 26.480 \\
IDE & Light Green & 10.743 & 20.835 \\
MAV & Brown & 60.843 & 63.931 \\
ORH & Pink & 46.965 & 44.956 \\
RAD & Gray & 32.390 & 26.480 \\
RBY & Black & 19.747 & 15.189 \\
STV & Dark Green & 66.319 & 99.117 \\
VLO & Green & 42.481 & 77.451 \\
\hline
\end{tabular}




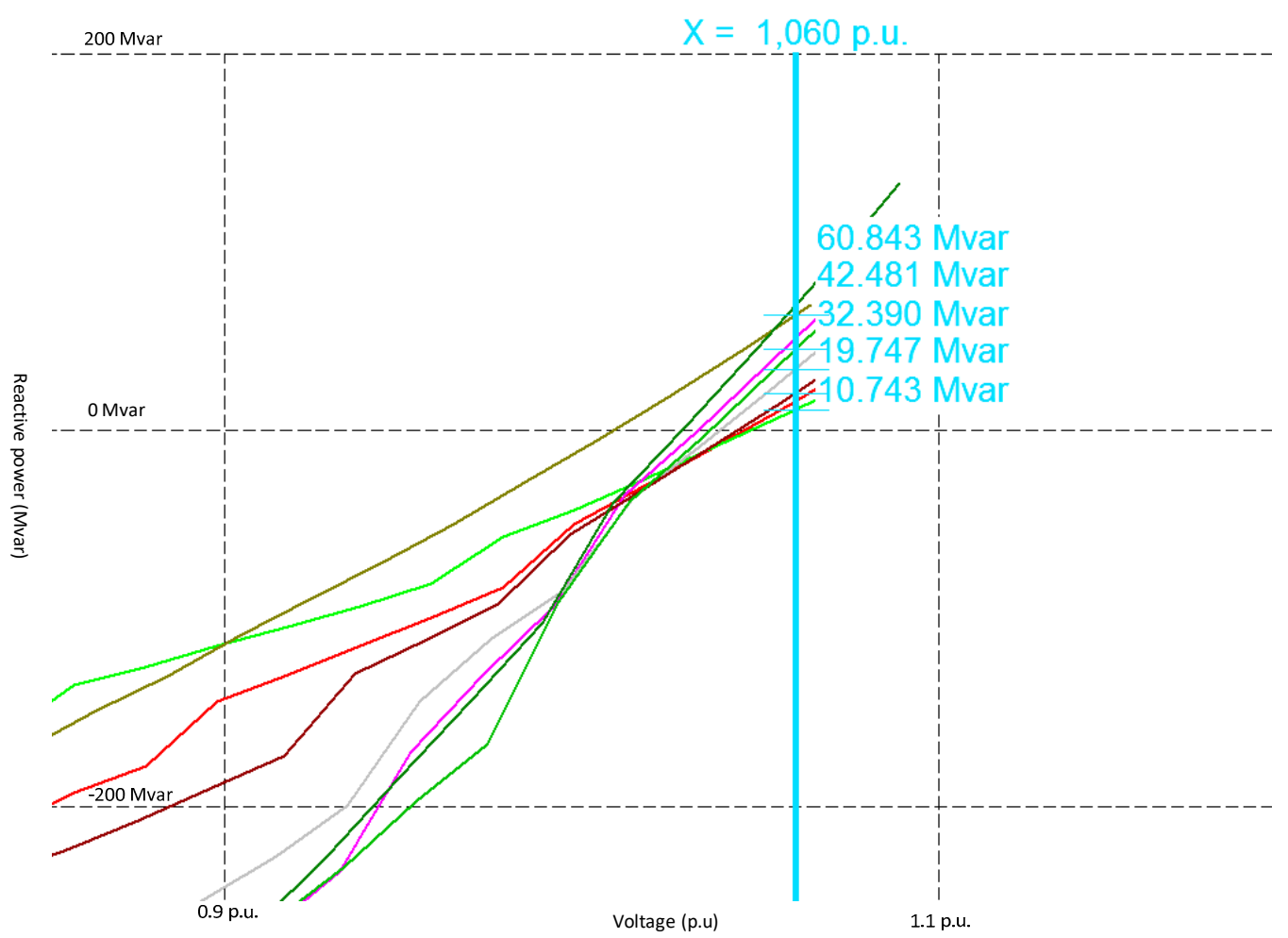

Figure 8. QV-analysis of the 3rd contingency, in the southern area of Zealand, after the added 100 Mvar reactor at RAD.

\subsection{Result}

When analyzing and designing the reactive power compensation, it is important to consider the criticality of the station. E.g., placing all the required reactive power at one station, as the case is showing in Figure 8, will make the system highly dependent on one station. For instance, in this case, it will be RAD. Due to the results from the analysis, it will be further investigated how to minimize such dependency.

The simplest solution will be to split the 100 Mvar reactor into two 50 Mvar reactors and place them on two separate stations. The two stations chosen for the placement of the two reactors were selected to shorten the distance between the other stations in the area. This would provide the system with some redundancy in terms of outages of a bus bar in the transmission system. The QV-analysis from this result is shown on the graph in Figure 9, where the colors of the curves are shown in Table 5. By splitting the 100 Mvar reactor into two 50 Mvar reactors, and installing them at VLO and ESK, the margin for STV, VLO, ESK, MAV, and IDE to the upper voltage limit increases. However, the margin for the stations RAD, RBY, and ORH to the upper limit decreases. The result of the comparison of the two cases, with 100 Mvar and two 50 Mvar reactors, is shown in Table 5.

The result of the analysis of the southern area was to give the system both the necessary redundancy and reactive power reserve. The compensation is divided into two shunt reactors, to meet the required reactive power. This requirement of reactive power, in the worst case, is therefore met by the addition of two 50 Mvar shunt reactors at VLO and ESK, as was the case for the QV-analysis at Figure 9. 


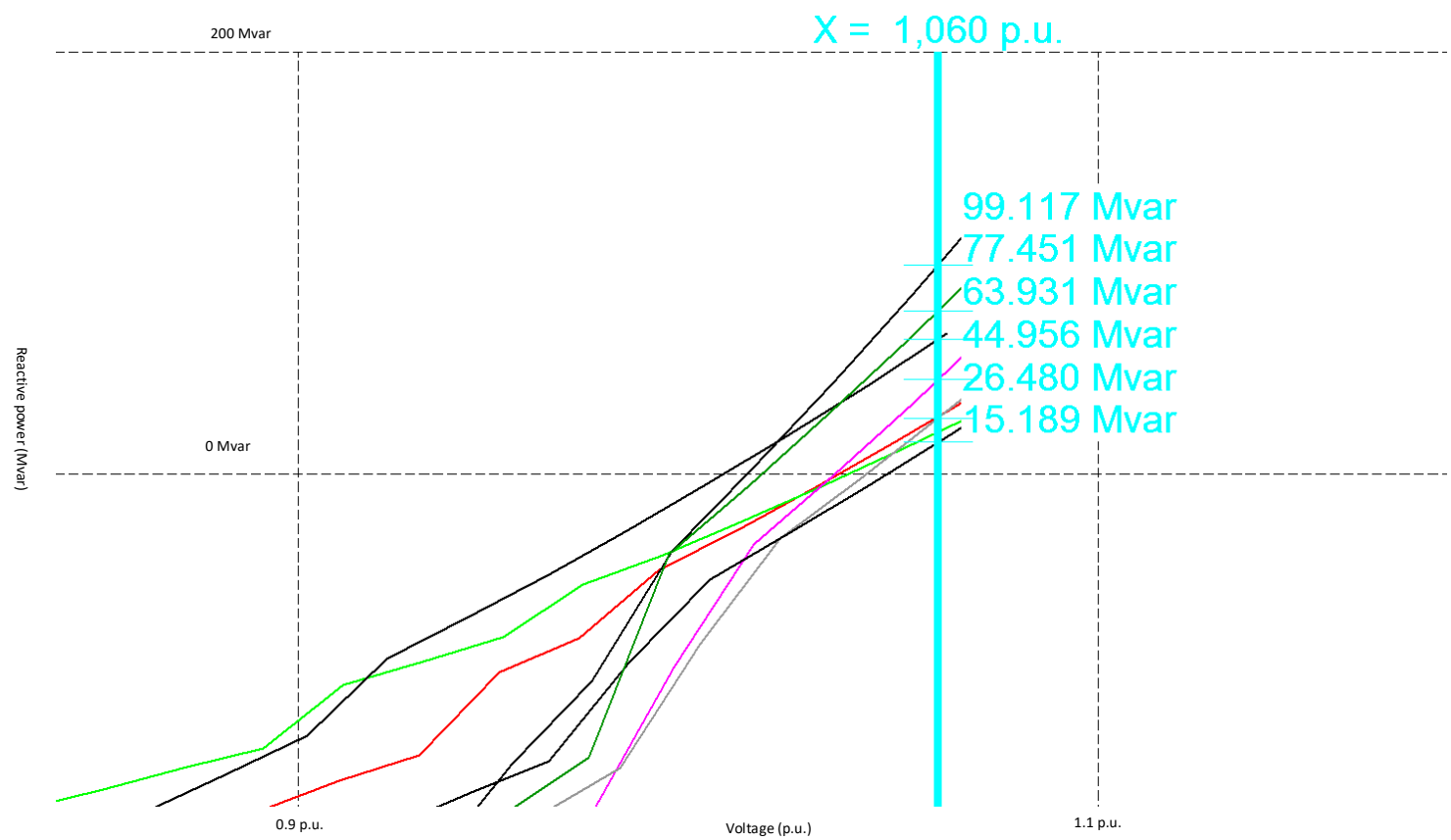

Figure 9. QV-analysis of the 3rd contingency, in the southern area of Zealand, after the added 100 Mvar reactor split on two reactors at VLO and ESK.

\subsection{Voltage Sensitivity}

One of the benefits by dividing the transmission network of Zealand into the 7 Mvar areas, as is shown in Figure $4 b$, is that it provides a much clearer overview of the system. This is especially beneficial in the QV-analysis, due to the voltage sensitivity, which is the slope of curves. This way of analyzing the transmission network showed a possible future issue, which the traditional way of investigating the required reactive power would not have shown. This is because higher voltage sensitivity is easier to regulate. However, this can be a challenge if the voltage sensitivity gets too high, as it could be the case for the station ØSH, in Figure 10. In this case, the slope of ØSH, the blue curve, might be something to be aware of due to the flat slope of the curve, which indicates a high voltage sensitivity. The voltage for ØSH is not above the limit in the N-2 event, which was determined from Table 3.

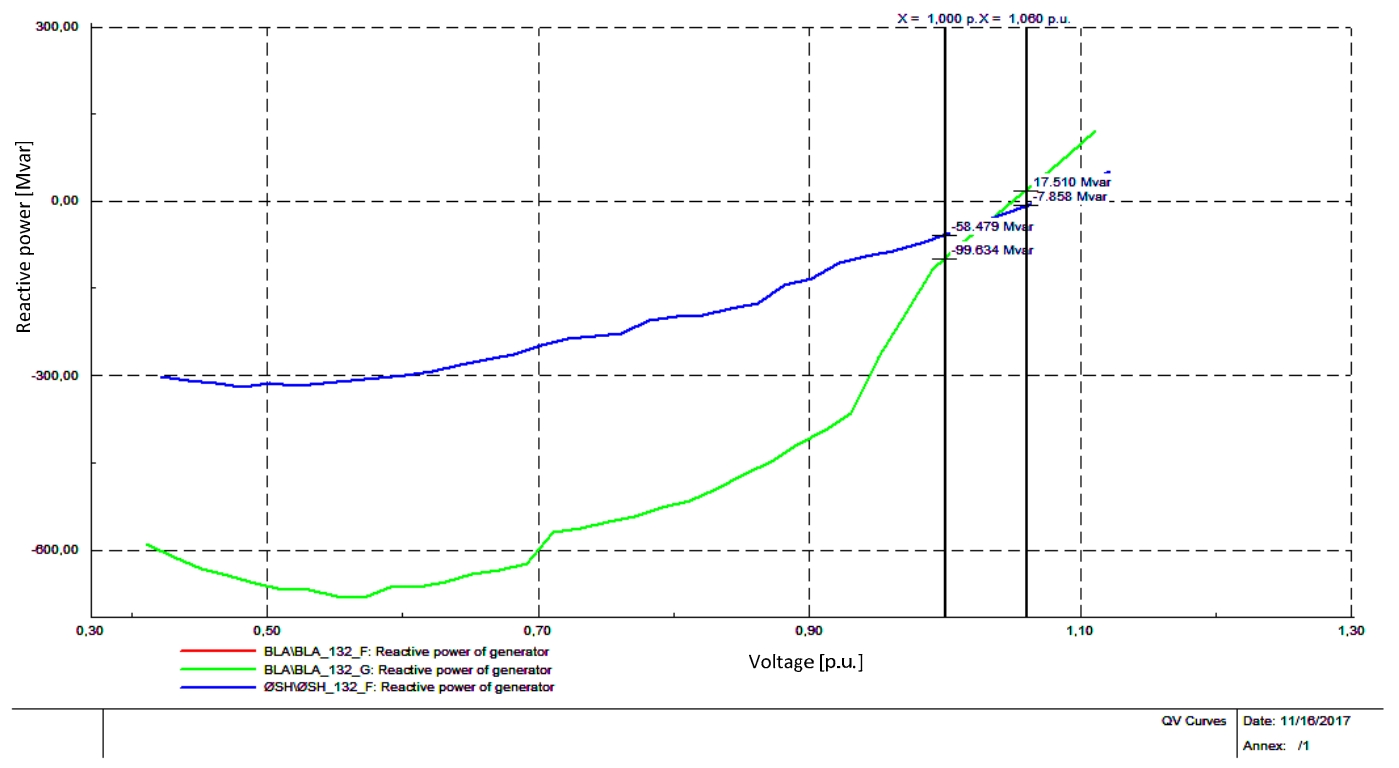

Figure 10. The QV-curves for two substations, BLA and ØSH, in an N-2 situation. 
Due to high voltage sensitivity [20], this bus bar is highly sensitive to changes in the reactive power. Changes in the reactive power could occur by changing OH-line to cables, which the Danish transmission grid is changing towards. In the analysis, the chosen dates were when the load of the line were low, and the transmission grid were or became highly capacitive. This is something to be aware of when a bus bar such as ØSH is sensitive, as is the case in Figure 10.

To illustrate the problem with high voltage sensitivity, a 100 Mvar capacitor was placed at $\varnothing \mathrm{SH}$, in Figure 11. The changes here were significant and could create problems, in the case of over compensating the grid or larger changes from OH-lines to cables.

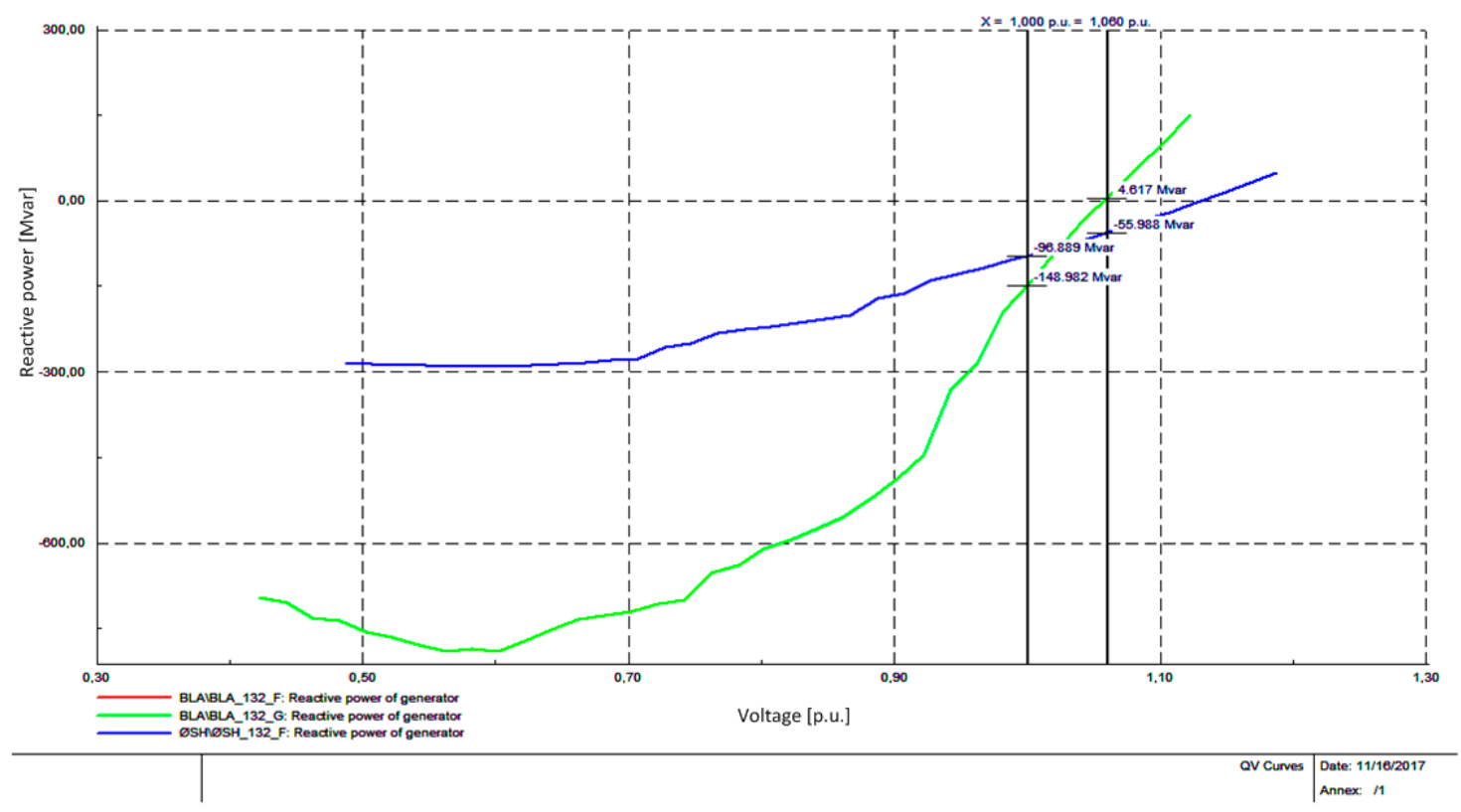

Figure 11. The QV-curves of two substations, BLA and ØSH, in a N-2 situation, with the addition of a 100 Mvar capacitor bank.

\subsection{Summary of the $Q V$-analysis}

In this section, a quick follow up on the entire QV-analysis will be presented. The defined Mvar area was originally divided into 5 different areas. The analysis showed that the areas, defined at first, were too large in some cases. In the cases where the areas were too large, it was not possible to calculate whether there was a requirement for reactive power compensation by choosing a bus bar in the dimensioning area.

The definition of both the new and original areas are shown in Figure $4 a, b$. Figure $4 b$ shows all the bus bars that were chosen to dimension the areas required for reactive compensation. Those are marked with a red dot. In each area, the calculation point was chosen in the central part of the area. The stations that may have a critical length for the output of this method have been marked with pink.

The chart in Table 6 shows the recommended installed compensation, which in all three cases are shunt reactors. This is due to the need for lowering the voltages in the defined contingencies in both cases. The analysis for the southern area is presented, and the solution with two reactors at VLO and ESK is described. A lack of inductive power at KRL is due to a disconnection of two lines, which isolates a small area. The approach for the QV-analysis for the other areas is the same as the one presented in this paper, and the analysis for the lack of reactive power at KRL will therefore not be presented in this paper. The stations where the recommended compensation has been installed are marked with blue dots in Figure $4 \mathrm{~b}$. 
Table 6. The recommendation of the placement for reactive power devices, based on the QV-analysis.

\begin{tabular}{cc}
\hline Busbar & Size Compensation Device (Mvar) \\
\hline KRL & -24 \\
ESK & -50 \\
VLO & -50 \\
\hline
\end{tabular}

\subsection{Discussion of the Result of the QV-analysis, Compared with the Traditional Method}

Traditionally the TSO and the DSO have been looked at as two separate systems, with the transformers as the exchange point. The traditional method for investigating the reactive power balance, and to determine the lack of reactive power in the system, does not take the dynamics of the system into account. This means that determining the required reactive power compensation by the method described in Section 3.1 gives a misguided picture of the requirement for reactive power compensation. The analysis performed in this paper shows a need for both capacitive and inductive power in the traditional method. However, the QV-analysis shows that in a lot of these cases the two systems compensate for each other. This was caused by the capacitive transmission system, which was compensated for by the inductive loads from the distribution system. This means that the high exchange between the TSO and DSO is not necessarily a bad thing. Furthermore, as has been explained in this paper, it is also easy to find the optimal placement. This was case for the $100 \mathrm{Mvar}$ inductive power, which was divided into two 50 Mvar reactors, by dividing the system into Mvar areas. Analyzing the system in the traditional way will not provide an optimal geographical location, but only show the required reactive power contribution in each specific exchange point, between the TSO and the DSO.

\section{Conclusions}

This paper maps and analyzes the reactive power balancing of the Danish transmission network. The QV-analysis has proven that both in normal operation $(\mathrm{N})$ and in $\mathrm{N}-1$ operational scenarios, there are no challenges with the reactive power balance. In the southern part of the transmission network, it was discovered in the analysis that there was a requirement in $\mathrm{N}-2$ for inductive power. In this case, the QV-analysis indicated a requirement for 100 Mvar reactor, to lower the voltage under the chosen margin. The conclusions from the analysis were to provide the system with the necessary redundancy. The 100 Mvar inductive compensation should be divided into two 50 Mvar reactors, at VLO and ESK. Furthermore, dividing the system into 7 areas and analyzing the reactive power balance for each area with a QV-analysis shows that this method could also be used to analyze future projects.

Author Contributions: The author contributions are listed as following: conceptualization, M.Ø.N. and E.K.J.; methodology, M.Ø.N.; software, M.Ø.N; validation, M.Ø.N and E.K.J.; formal analysis, M.Ø.N.; investigation, M.Ø.N.; resources, M.Ø.N; data curation, M.Ø.N. and E.K.J; writing-original draft preparation, M.Ø.N.; writing-review and editing, J.J. and Z.Z; visualization, M.Ø.N.; supervision, J.J. and Z.Z.; project administration, P.J.R.; funding acquisition, Z.Z.

Funding: This research received no external funding.

Acknowledgments: This paper has been supported by Energinet, with both guidance, data collection and a complete PowerFactory model of the area of Zealand. The authors would like to thank Energinet and DTU for the contribution to this paper.

Conflicts of Interest: The authors declare no conflict of interest.

\section{References}

1. Akagi, H.; Watanabe, E.H.; Aredes, M. Electric Power Definitions: Background. IEEE Instant. Power Theory Appl. Power Cond. 2017. [CrossRef] 
2. Bujal, N.R.; Hasan, A.E.; Sulaiman, M. Analysis of the voltage stability problems in power system. In Proceedings of the IEEE International Confrence on Engeenering, Technology and Technopreneuship, Kuala Lumpur, Malaysia, 27-29 August 2014; pp. 278-283.

3. Guimaraes, P.; Fernendez, U.; Ocariz, T.; Mohn, F.W.; de Souza, A.C.Z. QV and PV curves as a planning tool of analysis. In Proceedings of the IEEE International Conference on Electrical Utility Deregulation and Restructuring and Power Technologies, Weihai, China, 6-9 July 2011.

4. Adabayo, I.G.; Jimoh, A.A.; Yusuff, A.A. Identification of suiTable nodes for the placement of reactive power compensators. In Proceedings of the IEEE International Conference on Renewable Energy Research and Applications, Birmingham, UK, 20-23 November 2016.

5. ENTSO-E. Reactive Power Management at T-D Interface. ENTSO-E Guidance for National Implementation for Network, Brussels, Belgium. 16 November 2016. Available online: https:/ /docstore.entsoe.eu/Documents / Network\%20codes\%20documents/NC\%20RfG/161116_IGD_Reactive\%20power\%20management $\% 20$ at $\%$ 20T\%20and\%20D\%20interface_for\%20publication.pdf (accessed on 4 December 2018).

6. Available online: https://www.entsoe.eu/about/system-operations/\#regional-groups (accessed on 4 December 2018).

7. Kundur, P. Power System Stability and Control; Sec. 11.2; McGraw-hil: New York, NY, USA, 1993; pp. 639-654.

8. Kundur, P. Power System Stability and Control; Sec. 14.1; McGraw-hil: New York, NY, USA, 1993; p. 960.

9. Available online: http://osp.energinet.dk/_layouts/Markedsdata/framework/integrations/ markedsdatatemplate.aspx (accessed on 4 December 2018).

10. Rawat, M.S.; Vadhera, S. Analysis of wind power penetration on power system voltage stability. In Proceedings of the 2016 IEEE 6th International Conference on Power Systems (ICPS), New Delhi, India, 4-6 March 2016; pp. 1-6.

11. Mahmood, F.B.; Ahmad, S.; Mukit, G.; Shuvo, M.T.; Razwan, S.; Maruf, M.N.; Albatsh, F.M. Weakest location exploration in IEEE-14 bus system for voltage stability improvement using STATCOM, synchronous condenser and static capacitor. In Proceedings of the 2017 International Conference on Electrical, Computer and Communication Engineering (ECCE), Cox's Bazar, Bangladesh, 16-18 February 2017; pp. 623-629.

12. Energinet. Netdimensioneringskriterier for Net Over $100 \mathrm{kV}$, Puplic dokument (Danish); Fredericia, Denmark, 2013. Available online: https://www.google.com.hk/url?sa=t\&rct=j\&q=\&esrc=s\&source= web\&cd=1\&ved=2ahUKEwivo9CukpLgAhVOE4gKHTcECrwQFjAAegQIABAC\&url=https\%3A\%2F\% 2Fenerginet.dk\%2F-\%2Fmedia\%2FF737881B1E724E15B0EA64CC8410232E.pdf\%3Fla\%3Dda\%26hash\% 3D7D2F40D242F94F7D0CCFBB27C541CFEB2438465F\&usg=AOvVaw01T_nwBBWjD9S6wkdKIJIn (accessed on 4 December 2018).

13. Moger, T.; Dhadbanjan, T. A novel index for identification of weak nodes for reactive compensation to improve voltage stability. IET Gener. Transm. Distrib. 2015, 9, 1826-1834. [CrossRef]

14. Available online: https://www.entsoe.eu/publications/system-operations-reports/operation-handbook/ Pages/default.aspx (accessed on 4 December 2018).

15. Kumar, K.S.; Affijulla, S. Voltage stability and dynamic analysis of North-Eastern Indian power grid. In Proceedings of the IEEE International Innovative Applications of Computational Intelligence on Power, Energy and Controls with their Impact on Humanity, Ghaziabad, India, 18-19 November 2014.

16. Zhao, J.; Ju, L.; Luo, W.; Zhao, J. Reactive power optimization considering dynamic reactive power reserves. In Proceedings of the 2014 International Conference on Power System Technology, Chengdu, China, 20-22 October 2014; pp. 97-102.

17. Energinet Grid Codes. Technical Regulations 3.2.3 for Thermal Plants Above 11 kW; Public Document. Fredericia, Denmark, 2017. Available online: https://www.google.com.hk/url?sa=t\&rct=j\&q=\&esrc=s\&source= web\&cd=1\&cad=rja\&uact=8\&ved=2ahUKEwjZ5rPakpLgAhXQFogKHaXdDvQQFjAAegQICBAC\& url=https\%3A\%2F\%2Fen.energinet.dk\%2F-\%2Fmedia\%2F8C524C7E8092439D832748EC9D1E3022. PDF\%3Fla\%3Den\%26hash\%3DCDF75F22048131D157EB16A477016F1D53B67228\&usg=AOvVaw2E9J5H2tcvm5BHlEbBp_L (accessed on 4 December 2018).

18. Kundur, P. Power System Stability and Control; Sec. 14.4; McGraw-hil: New York, NY, USA, 1993; p. 1019. 
19. Reis, C.; Barbosa, F.M. A comparison of voltage stability indices. In Proceedings of the IEEE Electrotechnical Conference, Malaga, Spain, 16-19 May 2006.

20. Ting, D.; Xun, S. Network Static Voltage Stability Analysis Based on Sensitivity Analysis. In Proceedings of the 2011 7th International Conference on Wireless Communications, Networking and Mobile Computing, Wuhan, China, 23-25 September 2011; pp. 1-5. 